\title{
Evaluation of Anxiety Levels and Anger Styles of University Students
}

\author{
Leyla Tavacıŏlu ${ }^{1}$, Osman Kaan Kora ${ }^{2}$, Emel Yılmaz ${ }^{3}$, Evren Hergüner ${ }^{4}$ \\ ${ }^{1}$ Performance Analysis Laboratory, Maritime Faculty, Istanbul Technical University, Istanbul, Turkey \\ ${ }^{2}$ Department of Psychiatry, Marmara University Medical School, Istanbul, Turkey \\ ${ }^{3}$ Science Center, Istanbul Technical University, Istanbul, Turkey \\ ${ }^{4}$ Maritime Faculty, Istanbul Technical University, Istanbul, Turkey \\ Email: tavaciog@itu.edu.tr
}

Received June $15^{\text {th }}, 2012$; revised July $16^{\text {th }}, 2012$; accepted August $11^{\text {th }}, 2012$

\begin{abstract}
Anger is an emotion, which is useful if it is short-lived and of medium intensity, and which may be detrimental when it is continuous or severe. The aim of this study is to statistically evaluate the attitudes of university students towards anger and anxiety, and consequently towards violence. 150 subjects were randomly selected from among university students. Their anxiety levels were measured and evaluated pursuant to state and trait anxiety scale; trait anger levels and anger styles were measured and evaluated pursuant to trait anger and anger attitude scale, socio-demographic nature was measured and evaluated pursuant to structured scale, and all the data were evaluated by using the statistics programs spss 18.0. 15 girls $(10 \%)$ and 135 boys $(90 \%)$ formed the sample group. When the responses to the questionnaire are reviewed, it is observed that $30.7 \%$ of the students expressed that they witnessed violence in their families and among relatives, $47.3 \%$ expressed that they have been punished by their families, and only 4 out of 105 students who were involved in fight to date have expressed that they received legal penalty. The data that have been gathered suggest that there is a positive correlation between outward anger scores and higher level of anxiety amongst the students. This finding indicates that expression of anger may cause interpersonal conflicts, negative self-perception, and decreased self-esteem. There also exists positive correlation among responses to the effect that those who were involved in fight in the past were witnessed more severe reactions than punishment. Violence severely influences an individual physically, emotionally and socially.
\end{abstract}

Keywords: Trait Anxiety; State Anxiety; Anger Level; Anger Style

\section{Introduction}

Anxiety is defined as the feeling of nervousness and stress associated with the stimulation and activation of the organism (Gould et al., 2002). Martens defines anxiety as an imbalance between the demands of the environment and the demands of the individual. Several researchers have described anxiety as a multi-dimensional state characterised by three main components. These three main components are:

- Somatic (perceived physical activation degree).

- Cognitive (perceived worry, fear and similar emotions).

- Behavioural (changes in communication patterns).

In addition to these definitions of anxiety, there are also dimensions of state anxiety and trait anxiety. Although these two types of anxiety have distinct characteristics, there is an underlying anxiety process in both.

State Anxiety: may be defined as the emotional state which is characterized by subjective, consciously perceived feelings of worry and fear, accompanied by stimulation or activation in the autonomous nervous system (Spilberger, 1966). State anxiety may also be called as constantly changing trait component (Weinberg \& Gould, 2003). State anxiety experienced by a student before entering an exam that will highly influence his average score, and the anxiety before an exam the student will take during the semester will be different.

Trait Anxiety: The tendency of individuals to perceive most of the surrounding circumstances as a threat is defined as trait anxiety. This kind of anxiety is stable and continuous compared to state anxiety. The severity and duration of anxiety vary depending on the personality of the individual. Trait anxiety is not directly observed in the behaviours of the individual; it can be found out by looking at the severity and frequency of the state anxiety reactions that are observed at different times and at different conditions. According to this, individuals with high trait anxiety are hurt more easily and more frequently than individuals with low trait anxiety when faced with stress; and they experience state anxiety both more frequently and more severely.

With regard to the distinction between state anxiety and trait anxiety; both external and internal factors play role in the occurrence of state anxiety. It is an emotional state that emerges in the form of experiences that are perceived by the individual as or as if a real threat or that is experienced in an acute form (in that moment, in that situation). On the other hand, we can say that trait anxiety is anxiety that is created by the tendency of the individual to perceive and interpret the circumstances as a cause of stress, and that is experienced in a continuous and chronic manner (Sertbaş, 1998).

Trait anxiety is defined as the tendency of an individual to worry and feel anxious, to show excessive response under stress, and to give intensive excitement reactions independent of environmental conditions (İkizler, 1993). 
In short, we can define the temporary anxiety in certain situations as state anxiety, whereas, the anxiety that almost always exists in the individual in the form of a permanent personality trait as trait anxiety (Tavacıoğlu, 1999).

Characteristics such as anxiety, fear and worry are necessary and useful mechanisms that we possess inherently and that warn and protect us from threats of the external world. However, when these anxiety, fears and worries are severe and out of control, there emerge a group of psychiatric disorders called anxiety disorders, which influence and restrict the individuals' lives (Öztürk, 2008).

Why are anxiety disorders observed only in some people? Many factors play role in the development of anxiety disorders: e.g. genetic and environmental factors, childhood experiences, parental attitudes, stress, significant life events, our beliefs and how we cope with events. However, it would be wrong to argue that a single factor is influential on its own in the arise of anxiety disorders, because many factors must come together and interact. One of the factors that trigger the development of anxiety disorders is genetic predisposition. The studies made on this subject demonstrate that the likelihood to observe these kinds of disorders in persons who have close relatives like mothers, fathers, siblings, grandmothers, grandfathers with an anxiety disorder is higher compared to those who do not have any anxiety disorder in their families. However, this is only likelihood, and there is no rule that such a disorder will be observed.

Another factor that is influential in development of anxiety disorders is inclination factors, which are formed, primarily, by childhood experiences and parental attitudes. These inclination factors may be exemplified by incidents which deeply influence us during childhood, like the death of a beloved one, violence in the family, reactions of the parents towards events they experience, rigid, authoritative and restrictive parental attitudes or excessive sensitivity of the parent towards the child. These events and acts form an example for the children, and influence their reactions under similar circumstances and their skills to cope with these kinds of events in the future.

The effect of inclination factors arises when one experiences an event that creates severe stress in a matter which a person is sensitive on: such as losing a beloved one, witnessing an earthquake, acts of terrorism or war which cause traumatic stress, giving birth to a child, going through a serious illness or having a close relative who is sick. The stress and anxiety experienced as a result of these kinds of events is so intense that the anxietycoping methods used until that day may remain insufficient, and the person may start to develop methods that may cause problem in coping.

The critical point which leads to a problem in the persistence of anxiety related problems is the manner how a person perceives, interprets and evaluates a specific situation which he/ she is sensitive on; because the person perceives and evaluates that situation as a threat against him/her. After this point, we observe a cycle that is similar to anxiety disorders. Since the experienced situation is evaluated as a threat, it causes extensive trouble, uneasiness, and intense anxiety for the person. To cope, alternative, but problem-creating methods are used: such as avoiding similar situations. Although these negative methods reduce the anxiety in the short-term, they create problems in the long-run. The increased need to check when a person remembers that he/she might have left the ovens/taps open although he/she previously checked them; when a person does not go outside alone thinking that he/she will encounter a negative event outside if he/she is alone, and no one will help him/her; when a person does not speak in front of public because of the fear that he/she will be criticised/will receive negative feedback, when a person gives excessive reactions such as screaming, jumping and shouting when he/she sees a small and harmless spider can be listed as examples for negative methods that create problems in the long term (Yorulmaz \& Altın, 2007).

In order to be able to understand whether anxiety is useful or harmful, we must know two factors: 1) the degree of anxiety and 2) the level of difficulty of the task we aim to achieve. The intensity of the anxiety and the level of difficulty of the task we aim to achieve determine whether the anxiety is useful or harmful. It has been observed that anxiety is harmful when the aim is to achieve a task which contains quite complex cognitive transactions such as understanding and solving a difficult physics problem. However, the medium level anxiety observed in cases that require a simple transaction such as having pre-designated groups select specific objects has been helpful in starting and completing the task earlier (Cüceloğlu, 1997). Anxiety is measured by using self-assessment criteria. The most widely used scale is State-Trait Anxiety Inventory (STAI) that has been developed by Spielberger et al in order to differentiate between state and trait anxiety.

Anger is a natural emotion. However, if it is out of control and gains a destructive characteristic, it will lead to problems in the school-business life, interpersonal relations, and general quality of life. The underlying emotion in most of the personal and social problems (for example, child abuse, violence in family, physical or verbal aggressiveness, social violence) is anger. Anger occurs as a result of certain external and internal events. The reasons that lead to anger in general are inhibition, facing an unfair attitude, physical harm and injuries, abuse, frustration, being aggressed and threats. According to the literature, when we are angry, cognition, emotion, communication, affection become activated in interaction with each other and concurrently.

\section{Method}

Socio-demographic (age, gender, education, marital status) characteristics and clinical characteristics of randomly selected 150 students of the Istanbul Technical University were analysed by using data interrogation form. The severity of anxiety has been evaluated by using State and Trait Anxiety Scale (STAI). The scale which was translated into Turkish in 1975, and that underwent validity and reliability studies is comprised of state anxiety and trait anxiety scales comprised of twenty items each. The total score obtained out of both scales ranges between 20 80. High score indicates high anxiety level, whereas low score indicates low anxiety level (Lecompte, 1975; Savaşır, 1977). Trait anger level and anger attitude has been analysed by using Trait Anger and Anger Expression Scale (TAS). It is a selfassessment scale that measures emotion and expression of anger. It was developed by Spielberger in 1983, and its validity and reliability for our country was done by Özer (1994). The scale is made up of 4 sub-scales and 34 items, comprised of inward anger, outward anger, anger control and trait anger. High scores obtained from trait anger sub-scale indicate that the level of anger is high, high scores obtained from anger control sub-scale indicate that the anger can be controlled, high scores obtained from outward expression of anger sub-scale indicate that the anger is easily expressed; high scores obtained from 


\section{TAVACIOĞLU ET AL.}

inward expression of anger sub-scale indicate that the anger has been suppressed (Savaşır, 1977). When evaluating the data, the identification details of the individuals have been shown in numbers and percentages; in order to research the difference between the two groups, t-test was used, and in order to determine the correlation between the two variables, Pearson correlation test was used. The error level was chosen as $\alpha=0.05$. $p$ values equal to or lower than such value were interpreted that "there is statistically significant difference".

\section{Results and Discussion}

In the sample group, total 150 students comprised of 15 girls $(10 \%)$ and $135(90 \%)$ boys were taken within the scope of the evaluation (Tables 1-12).

Table 1.

The place where you grew up.

\begin{tabular}{ccccc}
\hline & Frequency & Percentage & Valid percentage & Total percentage \\
\hline Rural & 7 & 4.7 & 4.7 & 4.7 \\
Town & 23 & 15.3 & 15.3 & 20.0 \\
City & 120 & 80.0 & 80.0 & 100.0 \\
\hline
\end{tabular}

Note: $80 \%$ of the students evaluated grew up in cities, $23 \%$ grew up in towns, and $7 \%$ grew up in rural areas.

Table 2.

Punishment by parents.

\begin{tabular}{ccccc}
\hline & Frequency & Percentage & Valid percentage & Total percentage \\
\hline Yes & 71 & 47.3 & 47.3 & 47.3 \\
No & 79 & 52.7 & 52.7 & 100,0 \\
\hline
\end{tabular}

Note: $47.3 \%$ of the students evaluated were punished by their parents.

Table 3.

Favourite type of movie.

\begin{tabular}{ccccc}
\hline & Frequency & Percentage & Valid percentage & Total percentage \\
\hline Comedy & 51 & 34.0 & 34.0 & 34.0 \\
Adventure & 70 & 46.7 & 46.7 & 80.7 \\
Romance & 18 & 12.0 & 12.0 & 92.7 \\
Action & 11 & 7.3 & 7.3 & 100.0 \\
\hline
\end{tabular}

Note: $46.7 \%$ of the students evaluated like watching adventure, $34 \%$ comedy, $12 \%$ romance and $7.3 \%$ action genre.

Table 4.

Violence in family and among relatives.

\begin{tabular}{ccccc}
\hline & Frequency & Percentage & $\begin{array}{c}\text { Valid } \\
\text { percentage }\end{array}$ & $\begin{array}{c}\text { Total } \\
\text { percentage }\end{array}$ \\
\hline Yes & 46 & 30.7 & 30.7 & 30.7 \\
No & 104 & 69.3 & 69.3 & 100.0 \\
\hline
\end{tabular}

Note: $30.7 \%$ of the subjects witnessed violence in family and among relatives.
Table 5.

High alcohol consumption in family.

\begin{tabular}{ccccc}
\hline & Frequency & Percentage & $\begin{array}{c}\text { Valid } \\
\text { percentage }\end{array}$ & $\begin{array}{c}\text { Total } \\
\text { percentage }\end{array}$ \\
\hline Yes & 18 & 12.0 & 12.0 & 12.0 \\
No & 132 & 88.0 & 88.0 & 100.0 \\
\hline
\end{tabular}

Note: $12 \%$ of the students have in their families someone who consumes alcohol at a level that may influence his daily functions.

Table 6.

Use of drugs in the family for purposes other than treatment.

\begin{tabular}{ccccc}
\hline & Frequency & Percentage & $\begin{array}{c}\text { Valid } \\
\text { percentage }\end{array}$ & $\begin{array}{c}\text { Total } \\
\text { percentage }\end{array}$ \\
\hline Yes & 20 & 13.3 & 13.3 & 13.3 \\
No & 130 & 86.7 & 86.7 & 100.0 \\
\hline
\end{tabular}

Note: $13.3 \%$ of the subjects do not have anyone in their family who uses drugs for purposes other than treatment.

Table 7.

Beijing involved in fight at school between the frequent punishment by reason of fight.

\begin{tabular}{lcccc}
\hline & & \multicolumn{2}{c}{$\begin{array}{c}\text { Punishment by reason } \\
\text { of fight }\end{array}$} & \multirow{2}{*}{ Total } \\
\cline { 2 - 4 } & & Yes & No & \\
\hline $\begin{array}{c}\text { Being involved in } \\
\text { fight at school }\end{array}$ & Yes & 41 & 62 & 103 \\
\hline
\end{tabular}

Table 8.

High alcohol consumption.

\begin{tabular}{ccccc}
\hline & Frequency & Percentage & $\begin{array}{c}\text { Valid } \\
\text { percentage }\end{array}$ & $\begin{array}{c}\text { Total } \\
\text { percentage }\end{array}$ \\
\hline Yes & 15 & 10.0 & 10.0 & 10.0 \\
No & 135 & 90.0 & 90.0 & 100.0 \\
\hline
\end{tabular}

Note: $10 \%$ of the students consume alcohol at a level that may influence his/her daily functions.

Table 9.

For calming down...

\begin{tabular}{ccccc}
\hline & Frequency & Percentage & $\begin{array}{c}\text { Valid } \\
\text { percentage }\end{array}$ & $\begin{array}{c}\text { Total } \\
\text { percentage }\end{array}$ \\
\hline I go outside & 77 & 51.3 & 51.3 & 51.3 \\
I damage the goods & 14 & 9.3 & 9.3 & 60.7 \\
$\begin{array}{c}\text { I occupy myself with } \\
\text { something that I like } \\
\text { doing }\end{array}$ & 50 & 33.3 & 33.3 & 94.0 \\
$\begin{array}{c}\text { I apply physical } \\
\text { violence }\end{array}$ & 9 & 6.0 & 6.0 & 100.0 \\
\hline
\end{tabular}

Note: $51.3 \%$ of the students go out in order to calm down, $50 \%$ occupies himself with something he likes doing. 
Table 10.

When you see people fighting...

\begin{tabular}{ccccc}
\hline & Frequency & Percentage & $\begin{array}{c}\text { Valid } \\
\text { percentage }\end{array}$ & $\begin{array}{c}\text { Total } \\
\text { percentage }\end{array}$ \\
\hline I stop and watch & 23 & 15.3 & 15.3 & 15.3 \\
I do not care & 78 & 52.0 & 52.0 & 67.3 \\
$\begin{array}{c}\text { I support the one } \\
\text { who is rightful }\end{array}$ & 28 & 18.7 & 18.7 & 86.0 \\
$\begin{array}{c}\text { I support the one } \\
\text { who is physically } \\
\text { weak }\end{array}$ & 13 & 8.7 & 8.7 & 94.7 \\
I join the fight & 8 & 5.3 & 5.3 & 100.0 \\
\hline
\end{tabular}

Note: $52 \%$ of the students ignore when they see people fighting in the road, $18.7 \%$ choose to support the one who is rightful, $15.3 \%$ choose to watch.

Table 11.

Beijing involved in a fight between the frequency legal penalty for such fight.

\begin{tabular}{ccccc}
\hline & & \multicolumn{2}{c}{$\begin{array}{c}\text { Legal penalty for } \\
\text { such fight }\end{array}$} & \multirow{2}{*}{ Total } \\
\cline { 3 - 4 } & & Yes & No & \\
\hline Being involved in & Yes & 4 & 101 & 105 \\
a fight & No & 0 & 45 & 45 \\
Total & & 4 & 146 & 150 \\
\hline
\end{tabular}

Note: Only 4 out of 105 students who were involved in a fight were imposed legal penalty.

Table 12.

Against aggressive acts...

\begin{tabular}{ccccc}
\hline & Frequency & Percentage & $\begin{array}{c}\text { Valid } \\
\text { percentage }\end{array}$ & $\begin{array}{c}\text { Total } \\
\text { percentage }\end{array}$ \\
\hline $\begin{array}{c}\text { We must protect } \\
\text { ourselves }\end{array}$ & 95 & 63.3 & 63.3 & 63.3 \\
$\begin{array}{c}\text { We must respond } \\
\text { We must determine our }\end{array}$ & 6 & 4.0 & 4.0 & 67.3 \\
$\begin{array}{c}\text { attitude before the rival } \\
\text { finds the chance }\end{array}$ & 47 & 31.3 & 31.3 & 98.7 \\
$\begin{array}{c}\text { We do not do anything } \\
\text { Total }\end{array}$ & 2 & 1.3 & 1.3 & 100.0 \\
\hline
\end{tabular}

Note: $63.3 \%$ of the students think that you must protect yourself against aggressive acts, $31.3 \%$ think it is necessary to state one's attitude before the rival finds the chance.

\section{Analyses}

The findings obtained as a result of the analyses that were made in accordance with the purpose of the research indicate that there is a positive correlation with the outwardly expressed anger score of those whose state anxiety levels are high amongst the students in the sample group in our research. This data indicates that outward expression of anger may cause interpersonal conflicts, negative self-perception, and decreased self-esteem. Anger is a result that occurs in consequence of unsatisfied wishes, undesirable consequences and unmet expectations. When this finding is evaluated from this perspective, the students with high scores for these data may be experienceing more problems by reason of the responsibilities they have assumed in life, and they may be experiencing the feeling of anger more frequently by reason of these problems.

In addition, out of the students in our sample group, those who were involved in fight in the past think that they will be witness violence in the future. This seems to be a positive correlation. This finding clearly indicates that violence is learned and the harm caused by an environment of violence encountered in any time slot in life creates the anxiety for the future.

As the number of those who respond to the question "did your family punish you during your childhood" with "yes" increases, the number of responses to the question "were there anyone exposed to violence in your family or relatives during your childhood" with "yes" increases. The most prevalent form of violence observed is violence applied by the man toward the woman and the child within the family (Güneri, 1996; Republic of Turkey Prime Ministry General Directorate of Women's Status and Problems, 1998). In the report issued by World Health Organisation in year 2002, it is advised that violence is mostly observed in family environment and towards women (Kurg, 2002).

Research on violence against women - especially male partner violence-has increased. Since 2005, when the first results of the World Health Organization (WHO) Multi-Country Study on Women's Health and Domestic Violence were launched, the number of intimate partner violence prevalence studies increased fourfold, from 80 to more than 300, in 2008 (Moreno \& Watts, 2011).

There is a positive correlation between the responses given to the questions "did your family punish you during your childhood" and "did you see heavier reactions from your family than punishment", and these data have been found to be statistically significant.

In addition, there is again a positive correlation between the responses of those who were involved in a fight and the responses that they witnessed heavier reactions than punishment by their families. Violence influences the individual physically, emotionally and socially.

\section{Suggestions}

As a result of this study, we thought it would be appropriate to give training to some of the students on the definition of violence and the circumstances involving violence, and to direct them to counselling services.

In addition, today, stress, anxiety and depression are amongst the major psychological health problems in modern societies. The studies conducted indicate that 16 million people suffer from depression and 32 million people suffer from anxiety problems in USA. People generally refer to psychological counselling, drug treatment or both in order to cope with these problems. Lately, people have started to doing exercises in addition to treatment of these problems.

As a result of scientific studies carried out in recent years it has been concluded that exercising reduces anxiety and depression, helps in coping with stress, and has a positive effect on psychological health in general (Landers, 1999; Landers \& Arent, 2001). Stephens (1988) has analysed the data obtained from 56,000 participants and concluded that physical activity level has a positive correlation with the psychological health in USA and Canada. In another study that was conducted in Eng- 
land, it was understood that Londoners think that doing exercises is the most effective method in coping with depression (Weinberk \& Gould, 2003). In light of these data, we think that it is quite significant if the students of our faculty are directed to sports.

\section{REFERENCES}

Akdeniz, M. (2007). Anger management skills, anger control training effect of high school students. Master's Thesis, Cukurova University.

Cüceloğlu, D. (1997). People and behavior: The basic concepts of psychology. Istanbul: Remzi Bookstore.

Güneri, F. Y. (1996). Violence against women in the family, in the house of terror, violence against women. İstanbul: Mor Çatı Yayinlar1.

İkizler, C. (1993). Psychological factors affecting the success of the sport and psychological training. Doctoral Thesis, Marmara University.

Kurg, E. G. et al. (2002). World report on violence and health. Geneva: WHO.

Landers, D. M. (1999). The influence of exercise and mental health. In C. B. Corbin, \& R. P. Pangrazi (Eds.), Toward a better understanding of physical fitness and activity (pp. 137-143). Scottsdale, AZ: Holcomb Hataway.

Landers, D. M., \& Arent, S. M. (2001). Physical activity and mental health. In R. Singer, H. Hausenblas, \& C. Janelle (Eds.), Handbook of sport psychology (pp. 740-765). New York: Wiley.
Moreno, C. G., \& Watts C. (2011). Violence against women: An urgent public health priority, Bulletin of the World Health Organization, 89, 1-2. doi:10.2471/BLT.10.085217

Özer, A. K. (1994). Preliminary study of trait anger and anger expression scales. Turkish Journal of Psychology, 9, 26-35.

Öztürk, M. (2008). Anxiety disorders in children. Another Psychiatry and Thought Journal, 1, 103-108.

Savaşır, I. (1977). Cognitive-Behavioral therapy assessment, scales are frequently used. Ankara: Printing Ozyurt, Turkish Psychological Association Publications..

Sertbaş, G. (1998). GPregnant women with pre-natal and post-natal period examination of state-trait anxiety levels. Unpublished Ph.D. Thesis, İzmir: Ege University.

Spilberger, C. D. (1966). Theory and research on anxiety. In C. D. Spilberger (Ed.), Anxsiety and behaviour (p. 17). New York: Academic Press.

Stephens, D. E. (1988). Predictors of aggressive tendencies in girls basketball: An examination of beginning and advanced participants in a summer skill camp. Research Quarterly for Exercise and Sport, 72, 257-266.

Tavacioğlu, L. (1999). Sport psychology-Cognitive assessments. Ankara: Bagırgan Press.

Republic of Turkey Prime Ministry General Directorate of Women's Status and Problems (1998). Violence in the Family and Social Areas, Ankara, Turkey.

Yorulmaz, O., \& Altın, M. (2007). How do we protect the psychological health? II, adulthood and old age. Ankara: Middle East Technical University Publishing. 